\title{
O CALENDÁRIO ECOLÓGICO ESCOLAR: UMA EXPERIÊNCIA DE EDUCAÇÃO AMBIENTAL NO ENSINO FUNDAMENTAL I
}

\author{
J. P. FRANÇA ${ }^{1 *}$ e L. T.SOUZA NETO ${ }^{2}$ \\ 'Instituto Federal de Educação, Ciência e Tecnologia do Rio Grande do Norte - IFRN \\ ${ }^{2}$ Universidade do Estado do Rio Grande do Norte - UERN \\ julimar.franca@ifrn.edu.br*
}

Artigo submetido em fevereiro/2014 e aceito em novembro/2015

DOI: $10.15628 /$ holos.2015.1957

\section{RESUMO}

Os problemas ambientais presentes em âmbito global são uma patente manifestação da crise da civilização ocidental capitalista. Diante disso, somente uma grande mudança cultural, proporcionada por uma educação pautada em valores socioambientais voltados para preservação do planeta será capaz de mitigar os efeitos dessa catástrofe ambiental e superar esse dilema da espécie humana. Nesse sentido, o calendário ecológico definiu como objetivos trabalhar datas comemorativas voltadas para a educação ambiental por meio de atividades didático-pedagógicas; levar conhecimentos sobre o meio ambiente e seus problemas à comunidade escolar e inserir de forma multidisciplinar e contínua a educação ambiental no âmbito de algumas escolas de ensino fundamental I do município de Areia Branca-RN. Os objetivos do trabalho foram atingidos. Pelo fato dos subsídios e atividades realizadas pela equipe técnica possibilitaram aos professores trabalharem de forma interdisciplinar as datas comemorativas, estabelecendo um diálogo entre as várias disciplinas do contexto escolar. O projeto, diferentemente de outras atividades escolares voltadas para questão ambiental não foi uma atividade isolada, estanque, de modo que durante todo o ano letivo a questão ambiental esteve presente no cotidiano de cada escola, por meio das várias atividades realizadas.

PALAVRAS-CHAVE: Calendário, Ecológico, Educação, ambiental.

\section{THE SCHOOL ECO-CALENDAR: AN ENVIROMENTAL EDUCATION EXPERIENCE ON ELEMENTARY SCHOOL}

\begin{abstract}
Environmental problems nowadays in the global scope are a right manifestation of the crisis of the capitalist western civilization. Therefore, only a big cultural change, provided by a methodical education in socioenvironmental values directed to preservation of the planet will be able to mitigate the effects of this environmental disaster and overcome this dilemma of the human species. In this sense, the ecological calendar project had as purpose to work through the didacticpedagogic commemorative dates activities focused on environmental education; to bring knowledge about the environment and its problems to the school community
\end{abstract}

and put in a multidisciplinary and continuous way the environmental education in scope of some elementary schools of Areia Branca-RN. The original objectives were achieved. Since, subsidies and activities carried out by the technical team enabled to the teachers to work in an interdisciplinary way the commemorative dates, establishing a dialog among the various disciplines of the school context. The project, unlike other school activities focused on environmental issues, was not an isolated activity, tight, so that during all the school year the environmental issue was present in the daily of each school, through various activities.

KEYWORDS: Calendar, Ecological, Education, Environmental. 


\section{INTRODUÇÃO}

A humanidade vive atualmente uma profunda crise civilizatória, que está presente nos modelos atuais de esgotamento dos paradigmas político, econômico, institucional e moral vigentes. A maior expressão dessa crise é a questão ambiental, que tem representado uma grande ameaça à sobrevivência dos seres vivos e à própria perpetuação da espécie humana em escala global.

Na realidade, o advento do padrão social do ocidente, com sua ética antropocêntrica e seu paradigma de relação sociedade/natureza moldado no uso exacerbado dos recursos naturais, tem se constituído como o grande responsável por problemas ambientais tais como: o efeito estufa provocado pelas atividades antrópicas, o desaparecimento da camada de ozônio, o aquecimento global, a extinção das espécies e um conjunto de outros problemas que têm perturbado os ecossistemas planetários e toda a humanidade (GRÜN, 2009).

Somente uma grande mudança cultural, que tenha como base princípios socioambientais, será capaz de reverter os efeitos das ações do homem e impedir a grave catástrofe ambiental que vem atingindo a humanidade. Essa transformação só ocorrerá, realmente, mediante a construção de novos valores sociais e civilizatórios, voltados para a preservação e conservação da natureza e para a afirmação de uma nova ética centrada no respeito aos seres vivos e suas relações com o meio em que vivem.

Nesse sentido, a educação ambiental torna-se um instrumento capaz de promover a transformação cultural e a superação da crise ambiental e civilizatória que vivemos. Por sua vez, a disseminação de uma educação ambiental exige uma ruptura com toda a tradição paradigmática que fundamenta os modelos sócio-econômicos e pedagógicos vigentes.

Assim, este trabalho tem por objetivo descrever como o Município de Areia Branca tem trabalhado de forma interdisciplinar as questões ambientais relacionadas à educação ambiental e à participação democrática das escolas das zonas rural e urbana do município por meio de ações baseadas em datas comemorativas do Calendário Ecológico Escolar durante todo o ano letivo.

\section{A CRISE DOS PARADIGMAS TRADICIONAIS: CIENTÍFICO E ECONÔMICO}

A Europa passou por grandes mudanças socioeconômicas entre os séculos XVI e XVIII. Nesse momento histórico, sucumbiu a sociedade feudal e surgiu a ciência e a indústria moderna, transformando costumes, hábitos, tradições, modos de vida, visões de mundo e edificando um novo modelo de sociedade.

Pensadores como o matemático francês Renê Descartes, o físico inglês Isaac Newton e o astrônomo italiano Galileu Galilei deram grandes contribuições para a edificação da base científica moderna. Esses estudiosos, com suas teorias, romperam com o modelo orgânico de Aristóteles que concebia a natureza como algo vivo e passaram a pensar a natureza como uma grande máquina, como um relógio composto de pequenas peças que se combinam, formando uma grande engrenagem mecânica.

Assim, na ótica da ciência moderna, o homem deveria decompor essa grande máquina que são os sistemas naturais para poder conhecê-la. Somente por meio do conhecimento científico experimental, é possível conhecer, dominar e transformar completamente a natureza em função 
dos interesses materiais humanos. Para dominar a natureza e controlá-la, o ser humano precisa ficar fora dela. É a partir desse pressuposto que surgiu a dualidade natureza/cultura, sujeito/objeto. O homem deixou de ser mais uma espécie na natureza para se julgar o senhor absoluto dos recursos naturais. O mundo passou a ser concebido a partir dessa ética antropocêntrica que estimulou o desenvolvimento ilimitado dos sistemas econômicos em detrimento dos ecossistemas. De acordo com Grün (2009),

A ética antropocêntrica está intimamente associada ao surgimento e a consolidação daquilo que hoje chamamos paradigma mecanicista. Poderíamos dizer sem exagero nenhum, que a ética antropocêntrica é como se fosse à consciência do mecanicismo. Tal ética se afirma em consonância com a virada epistemológica caracterizada pelo abandono da concepção organísmica da natureza em favor de uma concepção mecanicista (GRÜN, 2009, p. 27).

Para os pioneiros da ciência moderna, todo o conhecimento sobre a natureza deveria ser fragmentado e traduzido em linguagem matemática e em relações mecânicas de causa e efeito. Essa fragmentação do conhecimento produziu a especialização científica e um conjunto de saberes reducionistas que passaram a captar apenas alguns aspectos da totalidade e complexidade que são os ecossistemas naturais.

Essa visão da natureza foi reforçada pela revolução técnica e industrial do século XVIII, que absolutizou a ideologia da produção em massa e do crescimento econômico a qualquer custo. Assim, a produção industrial em série e a noção de progresso, como aumento da produção material e crescimento econômico sem limites, se tornaram finalidades últimas da atividade econômica. A natureza tornou-se, desse modo, um mero fator de produção, um recurso econômico a ser explorado infinitamente para a produção de bens e serviços que deveriam satisfazer as infinitas necessidades materiais humanas. Para Camargo (2003), o estabelecimento de uma economia industrial urbana, com base numa tecnologia altamente consumidora de energia e matéria-prima, radicalizou o impacto do homem sobre a natureza.

Também no século XVIII, o advento da ciência econômica ignorou o valor e a finitude dos bens naturais e contribuiu enormemente para edificação da ideologia produtivista e do crescimento econômico. Para Adam Smith e os precursores da economia moderna, a natureza é um bem sem valor, somente após sofrer a ação do trabalho humano e ser transformada em bens ou serviços é que aquela adquire valor de troca e importância econômica.

Todavia, na segunda metade do século XX, esses paradigmas científicos e socioeconômicos apresentaram sinais de esgotamento. A fragmentação do conhecimento científico, as dualidades sujeito/objeto, natureza/cultura e o crescimento econômico sem levar em consideração a capacidade de carga do planeta conduziram a humanidade a uma grave crise ambiental pautada nos impactos ambientais e no advento do esgotamento dos recursos naturais, fazendo emergir a discussão sobre a construção de novos paradigmas e o papel da educação ambiental na solução da crise sócio-ambiental vigente.

\section{ASPECTOS HISTÓRICOS DA CONSCIÊNCIA DA CRISE AMBIENTAL E A EMERGÊNCIA DE UMA EDUCAÇÃO AMBIENTAL}


Até a década de 50, do século passado, a preocupação social com a preservação da natureza era praticamente um assunto isolado, apenas do interesse dos amantes da natureza e da comunidade científica. Na década seguinte, a sociedade civil em geral começou a tomar consciência de que a o planeta vivia uma crise ambiental e, concomitantemente, emergiu o discurso de que um dos instrumentos para o enfrentamento da crise de degradação dos ecossistemas seria a educação ambiental.

O grande marco introdutório da questão ambiental foi o livro Primavera Silenciosa, publicado em 1962 nos Estados Unidos, por Rachel Carson. Essa obra abordou os efeitos nefastos dos agrotóxicos para agricultura e o meio ambiente em geral. Atingindo um grande público, Carson alertou a sociedade para os problemas ambientais.

No final desta década, os movimentos de contra cultura também levantaram a bandeira da questão ambiental, questionando a cultura ocidental, criticavam os valores da sociedade moderna, sobretudo, o consumismo, defendendo o pacifismo e a preservação da natureza.

Nos anos 70, a questão ambiental chegou a esfera estatal e, em 1972, ocorreu em Estocolmo, na Suécia, a conferência das Nações Unidas sobre desenvolvimento humano. Nessareunião, que discutiu os problemas ambientais em nível global, também se afirmou que a educação ambiental é um elemento crítico capaz de educar os cidadãos para combater a crise ambiental (CAMARGO, 2003).

A crise do petróleo em 1973, que contribuiu para demonstrar a finitude dos recursos naturais, também ampliou o consenso social sobre a necessidade de pensar alternativas para a superação dos dilemas ambientais.

Diante da importância que a educação ambiental passou a receber no contexto de discussão da problemática ambiental. Em 1975, em Belgrado, na ex-lugoslávia, a UNESCO organizou o I encontro internacional de educação ambiental, Esse evento contou com a participação de 65 países e foi responsável pela formulação de alguns princípios e orientações básicas que foram utilizados na educação ambiental no mundo inteiro.

Em 1977, em Tbilisi (ex-URRS), ocorreu a conferência intergovernamental sobre educação ambiental. Tal conferência foi um dos mais relevantes eventos em termos de discussão da educação ambiental global. Em Tbilisi, estabeleceu-se o consenso de que a educação ambiental deveria fundamentar novos valores e uma nova ética voltada para a sustentabilidade ecológica e equidade social, além de contribuir para uma nova visão de mundo com base no diálogo entre os saberes (TORRES et al., 2009).

Em 1979, aconteceu na Costa Rica, o Seminário internacional de educação ambiental para América Latina, que contribuiu para sistematização e divulgação de uma educação ambiental mais focada na realidade socioeconômica local.

No final dos anos 70, a preocupação com a questão ambiental chegou ao Brasil. Após a anistia, muitos exilados retornaram com ideias sobre a preservação do meio ambiente, com a as quais os brasileiros haviam tido contato na Europa. Grün (2009) afirma que,

Inicialmente o ambientalismo não teve uma grande recepção no Brasil. Vítima de uma concepção estreita e preconceituosa, as ideias sobre preservação ambiental foram consideradas uma espécie de luxo. Um tipo de capricho ao qual poderiam se entregar os países do primeiro mundo(GRÜN, 2009. p.18). 
Nos anos 80, a opinião pública brasileira se tornou mais sensível à problemática ambiental e, em 1981, foi criada a política nacional de meio ambiente e o sistema nacional de meio ambiente, tendo como objetivo a manutenção da qualidade ambiental. Nesse contexto, a educação ambiental foi considerada um dos princípios de realização da política nacional.

Nessa década, também surgiu à discussão sobre os espaços institucionais de educação ambiental. Assim, em 1987, o conselho federal de educação decidiu sobre o caráter interdisciplinar da questão ambiental e determinou a não inserção da educação ambiental como disciplina escolar (RUSCHEINSK, 2012).

A constituição federal de 1988, a primeira da história que trouxe um capítulo tratando do meio ambiente, também destacou a função do poder público como promotor da educação ambiental para preservação do meio ambiente em todos os níveis de ensino.

Na conferência sobre meio ambiente, realizada no Rio de Janeiro, em 1992, a maior já realizada no gênero, a educação ambiental foi bastante discutida e sugeriu-se substituir o termo educação ambiental por educação para um mundo sustentável, mas não houve consenso. Apesar disso, um importante documento, denominado "Tratado de educação ambiental para as sociedades sustentáveis", foi um dos resultados dessa conferência que contribuiu para o desenvolvimento da educação ambiental em âmbito global.

No Brasil, o grande marco da institucionalização da educação ambiental foi à publicação dos Parâmetros Curriculares Nacionais (PCNs) em 1996, pelo Ministério da Educação. Esse documento definiu o meio ambiente como um tema transversal que deveria, desse modo, ser abordado pelas diferentes disciplinas no contexto escolar, além de incorporar os saberes culturais nessa dinâmica compreensiva da problemática ambiental.

Além disso, com a criação da Política Nacional de Educação Ambiental Brasileira, em 1999, as ações de educação ambiental deixaram de ser uma política de governo e passaram a ser uma política de Estado, estando, por conseguinte, presente no cotidiano da sociedade brasileira. De acordo com essa lei, "o princípio básico da educação ambiental é pensar o meio ambiente em sua totalidade considerando a interdependência entre o meio natural, social e cultural" (BRASIL. LEI $\mathrm{n}^{\circ}$ 9.795, de 27 de abril de 1999).

$\mathrm{Na}$ década seguinte, o grande desafio da educação ambiental no Brasil foi colocar em prática as leis responsáveis pela legalização dessa educação nos aspectos formal e informal. Apesar dos avanços nesse processo de institucionalização da educação ambiental, ainda há muito a ser construído, tendo em vista os desafios que existem no ato de romper com a pedagogia tradicional de base cartesiana-newtoniana.

\section{A EDUCAÇÃO TRADICIONAL, OS LIMITES E DESAFIOS NA CONSTRUÇÃO DE UMA EDUCAÇÃO AMBIENTAL ESCOLAR}

A implementação da educação ambiental no âmbito escolar constitui-se numa tarefa árdua e uma verdadeira revolução pedagógica e paradigmática. Assim, são incontáveis os desafios que devem ser superados para se construir uma educação centrada na questão ambiental dentro do atual sistema escolar. 
A educação na sociedade moderna, herdeira das revoluções do século XVIII, se universalizou-se centrada na ética antropocêntrica cartesiana e disseminou os dualismos natureza/cultura, sujeito/objeto, corpo/espírito, de modo que as próprias estruturas conceituais e curriculares da educação atual transformam-se em um empecilho à educação ambiental (LOUREIRO, 2012).

De acordo com Grün (1996), não é possível realizar uma educação ambiental nas estruturas conceituais cartesianas que caracterizam nossa educação. Pois as estruturas conceituais do currículo sugerem que o homem é referência única para todas as coisas existentes na Terra. Inúmeras expressões presentes nos livros e textos didáticos, como "Animais nocivos, raízes e caules úteis ao homem, importância dos recursos naturais para o homem" reforçam a tese do antropocentrismo presente no currículo escolar. Ademais, disciplinas como a física, a química e a economia ignoram a importância do meio ambiente, como se este não fosse o local onde ocorrem os fenômenos físicos, as reações químicas ou os processos econômicos que produzem os meios de existência responsáveis pela perpetuação da espécie humana.

Assim, pela própria lógica curricular da escola moderna, tem-se produzido poucos resultados no sentido de mitigar os impactos ambientais provocados pelo atual modelo civilizatório. Na realidade, a escola acaba atuando como reprodutora de uma ideologia e de uma cultura predatória ao meio ambiente que reforça a crise ambiental.

A educação atual também se baseia na especialização disciplinar cartesiana. De modo que, o conhecimento da realidade é totalmente fragmentado na organização curricular de nossas escolas. Alguns aspectos da realidade são estudados por determinadas disciplinas que, de forma isolada e limitada, procuram compreender o todo que é a realidade. Há em nosso sistema de ensino fronteiras e limites intransponíveis entre as disciplinas que, muitas vezes, se dedicam a estudar a problemática ambiental, de forma isolada.

Assim, a prática da interdisciplinaridade, essencial na educação ambiental se constitui em outro grande desafio. Na verdade, o entendimento da complexidade presente no meio ambiente só é possível por meio um diálogo interdisciplinar entre os saberes. O conhecimento disciplinar limitado não é capaz de formar uma geração que seja capaz de dar respostas à atual crise ambiental e aos seus complexos desdobramentos. Embora, as orientações do Ministério da Educação, por meio dos Parâmetros Curriculares Nacionais (PCN), tenham deixado explícito a transversalidade da questão ambiental. Essa situação também é deveras desafiante, visto que o diálogo entre os saberes não é uma prática comum no ambiente escolar.

Para Leff (2010), nenhuma ciência pode dar conta da questão ambiental. A disciplina só apreende parte do real. O saber disciplinar torna-se, por esse motivo, impotente diante da complexidade ambiental.

No entanto, só é possível trabalhar a educação ambiental, de verdade, no contexto escolar se ela estiver presente no projeto pedagógico, no currículo e no cotidiano escolar. Este também é um grande empecilho existente em nossas instituições de ensino pois a questão ambiental é trabalhada na maioria delas, por meio de projetos que acontecem em um determinado momento do ano letivo, de modo que a descontinuidade prejudica a produção de resultados satisfatórios. Para romper com a cultura predatória do meio ambiente, a temática ambiental deve ser discutida de forma contínua e permanente, estando presente em todos os dias e em todos os espaços de convivência e aprendizagem escolar. 
Infelizmente, nas escolas, alguns projetos isolados são assumidos por uma disciplina que, geralmente, tem mais afinidade com a questão ambiental ou, então, um único professor executa ações fadadas ao fracasso, por não conseguir trabalhar de forma transversal e nem representar os anseios de toda a escola, que permanece indiferente às ações executadas. Na verdade, a educação só acontecerá, de fato, se for assumida como um projeto de toda a comunidade escolar.

\section{O CALENDÁRIO ECOLÓGICO ESCOLAR}

A ênfase nas datas comemorativas do calendário civil é um instrumento pedagógico presente na educação brasileira. As escolas de Ensino Fundamental de diversas regiões do país trabalham, em seus currículos, datas comemorativas, objetivando resgatar fatos históricos relevantes e internalizar valores e tradições sociais em crianças e adolescentes.

Levando tal contexto em consideração, a equipe técnica da gerência executiva de gestão ambiental composta por um sociólogo e mestre em desenvolvimento, uma técnica em controle ambiental e um gestor ambiental, elaborou, no início do ano de 2011, o calendário ecológico escolar do município de Areia Branca.

O calendário ecológico definiu como objetivos: trabalhar, por meio de atividades didáticopedagógicas, datas comemorativas voltadas para a educação ambiental; levar conhecimentos sobre o meio ambiente e seus problemas à comunidade escolar; por fim, inserir, de forma interdisciplinar e contínua, a educação ambiental no âmbito das escolas de Ensino Fundamental I.

Por se tratar de uma experiência piloto, o projeto foi idealizado para ser realizado com 08 escolas de Ensino Fundamental I da rede municipal de ensino, das zonas rural e urbana da cidade. Foi escolhido esse nível de ensino pelo fato do destaque das datas comemorativas estarem em seu currículo e pela viabilidade de trabalhar as temáticas de forma multidisciplinar, visto que os professores, deste segmento de ensino, são polivalentes e trabalham com todas as disciplinas.

\section{METODOLOGIA}

Para o desenvolvimento das ações propostas pelo Projeto Calendário Ecológico, inicialmente, foram realizadas em cada escola municipal, reuniões com os docentes e a equipe pedagógica das instituições convidadas a participar do projeto. Na oportunidade, foi apresentada toda a metodologia do projeto e, assim, todas as instituições visitadas/convidadas aderiram voluntariamente à proposta.Assim os técnicos da gerência passaram a elaborar todo o material pedagógico composto por filmes, cartilhas, dinâmicas, músicas e outros recursos didáticos que seriam utilizados pelos professores nas salas de aula.

Após o começo das aulas, a partir do mês de março, todas as escolas foram visitadas novamente. Dessa vez, todos os docentes das oito escolas receberam o material didáticopedagógico e o calendário foi afixado nos murais escolares. Para facilitar o trabalho e manter a comunicação constante com as escolas, os subsídios (atividades impressas, vídeos e músicas temáticas, etc.) eram levados às escolas bimestralmente, de modo que periodicamente eram realizadas, em cada escola, reuniões com professores para avaliar a execução do projeto.

Além do trabalho realizado pelos professores em suas salas de aula, em cada data comemorativa, algumas escolas planejaram atividades coletivas que envolviam todos os alunos de 
cada turno escolar. Nas datas agendadas, a Gerência de Gestão Ambiental também realizou atividades massivas, envolvendo várias escolas e a comunidade em geral.

Na proposta para o desenvolvimento das atividades, foram escolhidas quinze datas a ser comemoradas no calendário ecológico e estão dispostas no quadro 1 :

Quadro 1 - Datas comemorativas desenvolvidas no Calendário Ecológico.

\begin{tabular}{|c|c|}
\hline Mês & Datas comemorativas \\
\hline \multirow{2}{*}{ Março } & 22 - Dia do turimo ecológico \\
\hline & 22 - Dia mundial da água \\
\hline \multirow{2}{*}{ Abril } & 22 - Dia do planeta terra \\
\hline & 28 - Dia da caatinga \\
\hline \multirow{2}{*}{ Maio } & $02-$ Dia do solo \\
\hline & 22 - Dia internacional da biodiversidade \\
\hline Junho & 01 a 05 -Semana do meio ambiente \\
\hline Julho & 26 - Dia da proteção dos manguezais \\
\hline Agosto & 27 - Dia da limpeza urbana \\
\hline \multirow{3}{*}{ Setembro } & 16 - Dia da proteção da camada de ozônio \\
\hline & 18 - Dia da limpeza do litoral \\
\hline & 21 - Dia da árvore \\
\hline \multirow{2}{*}{ Outubro } & 04 - Dia mundial dos animais \\
\hline & 12 - Dia do mar \\
\hline Novembro & $24-$ Dia do rio \\
\hline
\end{tabular}

Entre às atividades realizadas pela equipe da Gerência de Gestão Ambiental dentro do calendário, algumas mereceram destaque, como a visita de duas turmas de alunos da Escola Municipal Professora Geralda Cruz à futura Unidade de Conservação Dunas do Rosado, contando com a presença de técnicos do Instituto de Desenvolvimento Sustentável e Meio Ambiente do Rio Grande do Norte (IDEMA), que ministraram uma palestra no Ecoposto da futura Área de Proteção Amiental (APA); o pedágio no centro da cidade e visita a todas as escolas municipais com panfletagem nas salas de aula das escolas participantes do projeto; a visita aos quatro principais parques salineiros do Município com realização de palestras; e o plantio de mudas de manguezais (Figuras 1 e 2).

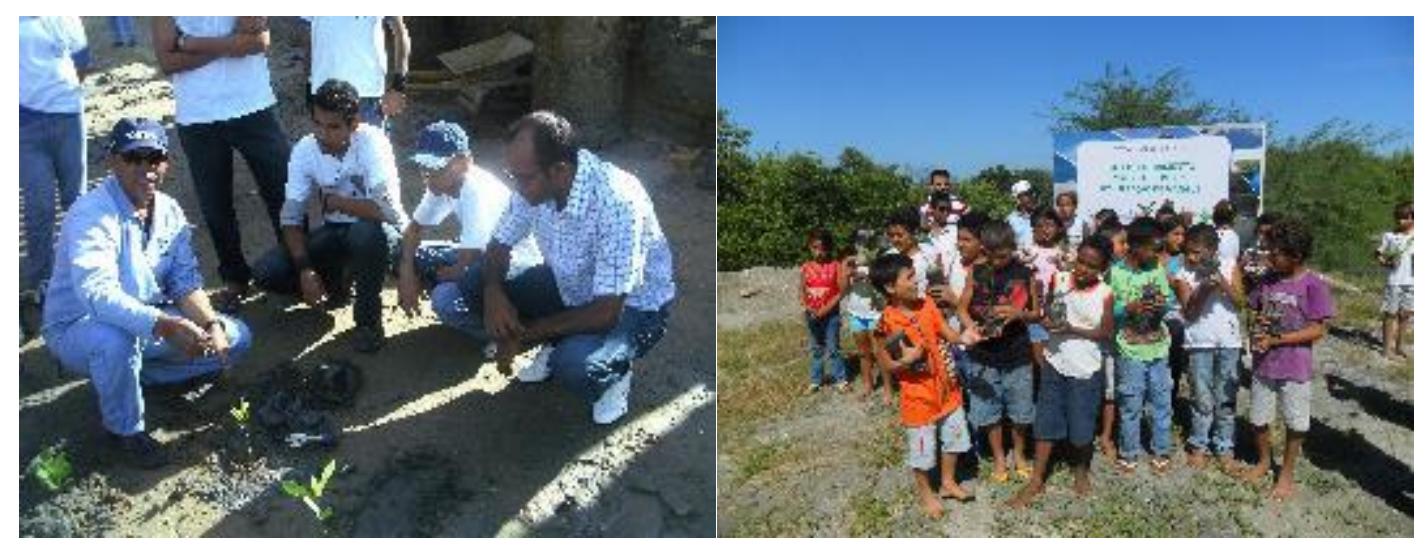

Figuras 1 e 2 - Plantio de mudas de manguezais nas salinas do município

As atividades do Calendário Ecológico contaram, ainda, com a realização de um teatro de fantoches sobre a importância da coleta seletiva, a visita do mascote da coleta seletiva local 
(Associação ROTATIVA) em todas as escolas e a realização do mutirão de limpeza nas praias do Município de Areia Branca com alunos de duas escolas (Figura 3).

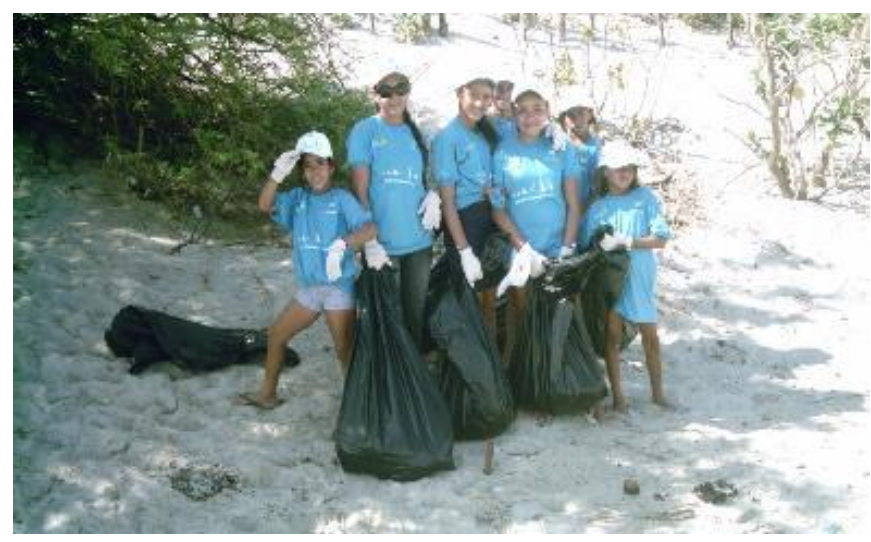

Figura 3 - Mutirão de limpeza

Na zona urbana, desenvolveu-se o plantio de mudas e a realização de palestra sobre a importância da arborização urbana nas escolas que não possuíam áreas arborizadas. Além disso, decorreu-se a organização de aula passeio no Rio Ivipanim com alunos das escolas Vingt Rosado, Valdeci Nunes e Aluísio Alves.

Entre os dias 1 e 5 de junho, foi realizada a Semana do Meio Ambiente (Figuras 4 e 5), com realização de gincana, passeio ciclístico e dia de convivência com alunos das escolas municipais.

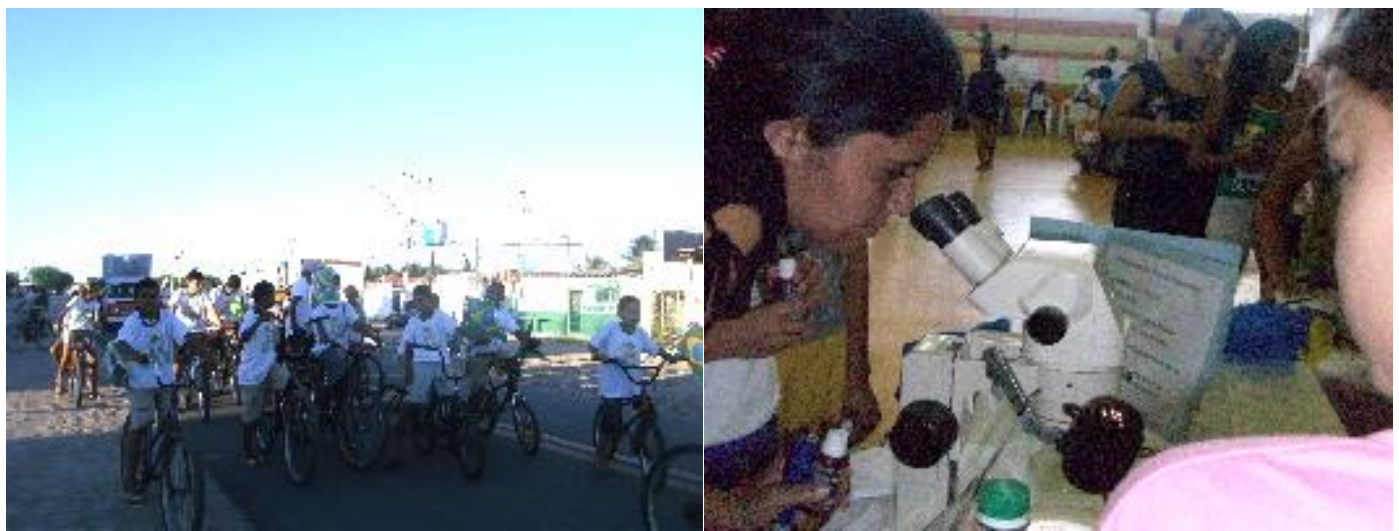

Figuras 4 e 5 - Semana de meio ambiente

É importante destacar, por fim, que a divulgação das atividades era realizada por meios de comunicação local (emissoras de rádio e Blogs), além da fixação de cartazes em escolas e órgãos públicos municipais.

\section{RESULTADOS E DISCUSSÕES}

O Projeto Calendário Ecológico apresentou como um dos objetivos, trabalhar, de forma interdisciplinar, questões ambientais relacionadas às datas ambientais comemorativas durante todo o ano letivo em um conjunto de ações, em escolas das zonas rural e urbana do município. 
Um primeiro desafio, nesse sentido, foi estabelecer o diálogo e o convencimento dos docentes com relação à relevância desse trabalho de educação ambiental em todos os estabelecimentos de ensino. Nas reuniões, bastante participativas realizadas no início do período letivo, os professores e as equipes pedagógicas fizeram questionamentos pertinentes sobre a metodologia e o desenvolvimento das atividades no ambiente escolar, possibilitando esclarecimentos e adequações nas ações propostas para o projeto. Nesse caso, havia uma preocupação dos educadores com relação ao suporte técnico e pedagógico que a equipe da gestão ambiental proporcionaria para a abordagem das temáticas em sala de aula e a realização das atividades propostas no calendário.

A questão ambiental é algo complexo que perpassa a totalidade da vida social. Nesse sentido, os Parâmetros Curriculares Nacionais do Ensino Fundamental brasileiro colocam o meio ambiente como um tema transversal, que deve ser contemplado pelas várias disciplinas do contexto escolar. Apesar disso, abordar essa temática, de forma transversal e interdisciplinar, tem se constituído em um enorme desafio nas várias atividades de educação ambiental realizadas na educação formal.

Segundo Torres, Leandro e Rebouças (2009, p. 10), “a Educação Ambiental, portanto, é um processo educativo mais profundo que vai além dos conteúdos e segue no sentido da formação de cidadãos conscientes e ativos". É, nesse caminho, que se objetiva o desenvolvimento de ações com esse contexto que tenha como viés a inclusão de alunos dentro das temáticas ambientais locais e globais para que tais sujeitos possam construir os seus pensamentos críticos e analíticos sobre o ambiente onde estão inseridos e sobre a importância de ver a realidade de forma holística.

Assim, o calendário ecológico foi elaborado, tendo em vista o enfoque das temáticas, de forma interdisciplinar, estabelecendo um diálogo entre os vários saberes escolares presentes na discussão dos assuntos estudados. O fato de um único professor trabalhar com as turmas facilitou a construção desse diálogo entre os saberes. As atividades sobre o dia do manguezal, por exemplo, foram introduzidas por meio de um resgate da História do município, demonstrando o processo de ocupação e construção de salinas, produção do sal e a consequente degradação do manguezal. Nessa aula, foram repassados concomitantemente, conhecimentos pertinentes e relacionados ao tema nas ciências naturais, geografia e da história.

Nas várias visitas técnicas realizadas nas salinas locais, técnicos, engenheiros químicos, engenheiros de produção e biólogos estabeleceram diálogos interdisciplinares a partir dos seus saberes e fazeres científicos e transmitiram informações importantes e motivadoras da aprendizagem aos estudantes de várias escolas.

No dia da limpeza urbana, os subsídios trabalhados também estabeleceram um diálogo entre conhecimentos de várias disciplinas (história, geografia, matemática, português e ciências naturais) para explicar o surgimento da sociedade industrial e de consumo, foram trabalhados conhecimentos das ciências humanas, na discussão sobre os danos ao meio ambiente, provocados pelos resíduos sólidos em que destacou-se conteúdo das ciências da natureza.

Isto posto, o calendário ecológico possibilitou o trabalho interdisciplinar, proporcionando subsídios para que o professor tivesse oportunidade de abordar as várias temáticas, rompendo com o tradicional cartesianismo que caracteriza a formação dos docentes e a prática pedagógica em nossas escolas. 
Ademais, outra característica bastante presente nos projetos de educação ambiental realizados nas escolas é a descontinuidade. Geralmente, essas atividades ocorrem em momentos isolados do ano letivo e abordam questões que ficam no ostracismo durante o restante do ano referido, impedindo uma efetiva internalização de valores e desenvolvimento de competências, ligadas à transformação das relações homem/natureza.

Diante disso, as atividades do calendário foram distribuídas durante todo o período letivo, de modo que os conteúdos, habilidades e valores foram trabalhados, de forma contínua, no sentido de desenvolver competências e formar um sujeito ecológico. Os avanços nesse sentido, foram relatados por docentes de algumas instituições que perceberam, no cotidiano escolar após a realização do projeto, mudanças de atitudes em questões como, acondicionamento do lixo em sala de aula, conservação do ambiente escolar e preocupação com o desperdício de água em seus alunos.

Um consequente e importante avanço resultante do projeto foi a contextualização dos conteúdos no enfoque das questões ambientais. Inúmeras atividades de educação ambiental abordam temáticas como efeito estufa, aquecimento global, poluição atmosférica, chuva ácida e outros temas que estão muitas vezes distantes da realidade do estudante. No calendário ecológico, a maior parte dos assuntos abordados fazia parte do cotidiano dos educandos em suas famílias e no próprio ambiente escolar. Assim, os subsídios trabalhados possibilitaram uma aprendizagem bastante significativa e um envolvimento de crianças e adolescentes com as temáticas discutidas, visto que as situações problemas eram vivenciadas pela maioria deles ou pelos seus familiares.

As aulas de campo realizadas com alunos de diferentes escolas caracterizaram-se como momentos singulares e importantes de aprendizagem significativa e contextualização dos conteúdos, alguns dessas aulas de campo, de acordo com os docentes, foram mais relevantes do que dias de aulas teóricas, visto que tais momentos podem se tornar experiências lembradas por toda a vida escolar.

\section{CONSIDERAÇÕES FINAIS}

Apesar dos desafios que são inerentes a qualquer atividade de educação ambiental, a implantação do calendário ecológico foi bastante exitosa. Pois os objetivos propostos, inicialmente, foram atingidos. Visto que, os subsídios produzidos pela equipe técnica possibilitaram aos professores trabalhar, de forma interdisciplinar, as datas comemorativas, estabelecendo um diálogo entre as várias disciplinas do contexto escolar. O projeto, diferentemente de outras atividades escolares voltadas para questão ambiental, não foi uma atividade isolada, estanque, de modo que durante todo o ano letivo a questão ambiental esteve presente no cotidiano de cada escola, por meio das várias atividades realizadas.

Ademais, a ênfase em temáticas locais possibilitou aos educandos o conhecimento sobre problemas ambientais que, geralmente, eram ignorados quando se trabalhava a questão no cotidiano da sala de aula.

Embora, no ano de 2013, algumas escolas tenham solicitado à Gerência de Meio Ambiente a continuidade do projeto, problemas de ordem material e técnicos inerentes ao poder público municipal inviabilizaram a realização do projeto que só foi retomada no ano de 2014, pela nova gestão municipal. 


\section{REFERÊNCIAS}

1. BERNA, V.S.D. Como fazer educação ambiental. São Paulo: Paulus, 2001. (Pedagogia e educação).

2. BRASIL. Lei $n^{\circ} 9.795$, de 27 de abril de 1999. Dispõe sobre a educação ambiental, institui a Política Nacional de Educação Ambiental e dá outras providências. Brasília, 1999.

3. CAMARGO, A.L de B. Desenvolvimento sustentável: Dimensões e desafios(Coleção Papirus Educação). Campinas: Papirus, 2003.

4. GADOTTI, M.. Educar para sustentabilidade. São Paulo: Editora e livraria instituto Paulo Freire, 2009. (Série unifreire: 2 )

5. GRÜN, M. Ética e educação ambiental: A conexão necessária. 12. ed. Campinas-SP: Papirus, 1996. (Coleção magistério: Formação e trabalho pedagógico).

6. JÚNIOR, L.A.F. Encontros e caminhos: Formação de educadores ambientais. Brasília: MMA. Diretoria de educação ambiental, 2005.

7. LEFF, E. Epistemologia ambiental. 5. ed. São Paulo: Cortez, 2010.

8. LOUREIRO, C.F.B. Trajetória e fundamentos da educação ambiental. 4. ed. São Paulo: Cortez, 2012.

9. C.F.B. (org.). Sociedade e meio ambiente: A educação ambiental em debate. São Paulo: Cortez, 2000.

10. REIGOTA, M. O que é educação ambiental. 2. ed. São Paulo: Brasiliense, 2009. (coleção primeiros passos: 292).

11. RODRIGUEZ, J. M. M; SILVA, E.V. da. Educação ambiental e desenvolvimento sustentável: Problemática, tendências e desafios. Fortaleza: Edições UFC, 2009.

12. RUSCHEINSKY, A. (org.). Educação ambiental: Múltiplas abordagens. 2. ed. Porto Alegre: Penso, 2012.

13. SILVA, E.L,MENEZES, E.M. Metodologia da pesquisa e elaboração de dissertação. 2. ed. Florianópolis: Laboratório de ensino à distância da UFSC, 2001.

14. TORRES, M. B. R. et al. (org.). Teorias e práticas em educação ambiental. Mossoró: UERN, 2009.

15. TORRES, M. B. R.; LEANDRO, A. L. A. L.; REBOUÇAS, J. P. P. Construindo outro diálogo entre sociedade e ambiente: a arte de conviver e (re) interpretar. In. RIBEIRO, M. R. F. et al. (org.). Educação Ambiental: construindo práticas, tecendo caminhos, semeando mudanças. Mossoró: Fundação Vingt-Un Rosado, 2009. 